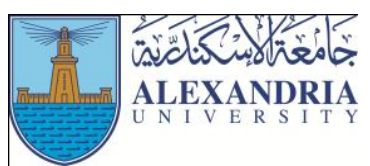

\title{
Effects of Taper on Elite Collegiate Female Judokas
}

\author{
Ahmed M. Ghazy ${ }^{1}$, Mahmoud E.Baioumy ${ }^{2}$, May A. Hamouda ${ }^{2}$ \\ ${ }^{1}$ PhD in Physical Education; Lecturer of Judo Faculty of Physical Education ; Head Coach of Judo Team - Tanta University, \\ Egypt \\ ${ }^{2}$ Lecturer, Department of Combat and Individual Sports - Faculty of Physical Education - Tanta University, Egypt
}

\begin{abstract}
:
The research aims to identify the effects of re-taper on physical, physiological and (SJFT) variables for elite collegiate female judokas. The researchers used the experimental approach (one-group design) with pre-and post-measurements. Six elite female judokas of Tanta University Judo Team (light weights of 48kg, 52kg and 57kg) who were under preparation for the Egyptian Collegiate Championship (43) during the academic year 2015-2016 were purposefully chosen to participate. The researchers used some physical tests and (SJFT). A re-taper program with low volume and progressive decrease of intensity from 80 to $60 \%$ was designed. Results indicated that re-taper program showed statistically significant differences between pre- and post-measurements of physical variables with high effect size ranging from (2.57) to (4.12) in favor of post-measurements. There are statistically significant differences between preand post-measurements of number of throws with high effect size ranging from (2.85) to (3.62) in favor of postmeasurements, and statistically significant differences between pre-and post-measurements of pulse rates with high effect size ranging from (1.12) to (1.96) in favor of post-measurements. Re-taper program showed statistically significant differences between pre-and post-measurements of SJFT with effect size (1.83) in favor of post-measurements. Results also indicated that SJFT index for participants was (12.84) which means that special judo fitness of participants is very high after re-taper.
\end{abstract}

Keywords: Re-taper-Pre-competition preparation - Special judo fitness

\section{Introduction:}

$\mathrm{T}$ aper is a recovery technique used before competitions to recover from stress resulting from high intensity training (Farhangimaleki, et.al.,2009). Through taper, we can decrease physiological and psychological stress of daily training on athletes in addition to increasing their athletic performance (Mujika, et.al.,2004).

Taper can be categorized into three types. Major taper lasts for 2-4 weeks for preparing to major competitions during the training season. Minor taper lasts for one week or less to achieve good performance level at the midseason. Re-taper is used when two competitions are within 3-5 weeks. It is used for maintaining or improving performance after major taper followed by a major or minor competition (Al-Qot 2013).

Coaches use taper to decrease training loads so as to help athletes recover from training stress before major competitions to increase optimum competitive performance during competitions (Hellard et.al.,2013; Bosquet, et.al., 2007; Mujika\& Padilla ,2003).
Although it is important to organize training according to the characteristics of taper stage, many coaches are not sure of its importance and mostly depend on trial and error to achieve optimum performance level instead of depending of a science-based strategy (Hellard et.al.,2013). Some athletes and coaches still think that taper may lead to detraining and has negative effects on performance (Houmard, et.al.,1994).

There are several ways for calibrating taper load as some coaches do it with high intensity low volume exercises while others do it with low intensity and moderate volume or complete rest (Al-Qot, 2013;Neary, et.al.,2003).During taper, training volume, intensity and frequency can be modified according to factors including pre-preparation, stress level and type and importance of competition (Coutts, et.al.,2007).

A judoka needs her full power and abilities in competitions to gain a medal as one match requires the judoka to perform a huge number of technical skills in addition to more motor power the body is under high levels of stress for prolonged durations and this leads to 
physical and mental fatigue (Umeda et al 2008). A typical judo match lasts for 3-4 minutes with 20-30 seconds of activity separated by 5-10 seconds of rest intervals (Anzano \& Llorens.1997).

Elite medalist judokas in major competitions usually fight 5-7 matches per day (Franchini et al 2011). Female Collegiate judokas participating in Egyptian Collegiate championships fight 3-5 matches in less than 2 hours one weight competition - at the day of championship. Judokas who are not well-prepared to such conditions may suffer from early fatigue and weak ability to continue fighting effectively and of course this means to lose and leave the championship very early.

Therefore, training volume should decrease near competition so that a judoka is at peak performance nearly on the third or second week before major competition. Then, performance intensity decreases gradually from the third week until competition(Nishioka 2000).

The researchers reviewed related studies to the effects of taper on athletes. Some studies like (Fukuda et.al.2013; Karimi, et.al.2013) indicated the importance of taper in improving physical, technical, skills, tactical, psychological and emotions conditions of athletes at the end of heavy training in pre-competition preparation stage.(Karimi, et.al. 2014 ; Mehranpour, et.al.2015; Baioumy \& Ghazy, 2015) indicated that pre-competition taper is suitable for improving competitive performance of athletes. The researchers noticed a sever lack in studies dealing with taper for female judokas on the national and Arab levels.

\section{Aim:}

To identify the effects of re-taper on physical , physiological and (SJFT) variables for elite collegiate female judokas.

\section{Hypotheses:}

1- There are significant differences between the pre- and post-measurements of physical and physiological variables in favor of the post-measurements.

2- There are significant differences between the pre- and post-measurements of (SJFT) in favor of the postmeasurements.

\section{Methods:}

Approach: Experimental approach (one-group design) with pre- and post-measurements.
Participants: Six elite female judokas of Tanta University Judo Team (light weights of $48 \mathrm{~kg}, 52 \mathrm{~kg}$ and $57 \mathrm{~kg}$ ) who were under preparation for the Egyptian Collegiate Championship (43) during the academic year 2015-2016.

\section{Data collection tools:}

Equipment: Medical balance -Restameter Dynamometer-Stopwatch - Measuring tape - Polar watch.

\section{Tests and measurements:}

According to Torfa (2001) and Baioumy \& Ghazy (2015) the researchers used the following tests:

- Physical variables: Vertical jump (Leg speed strength)Standing Long Jump (Leg speed strength) - Lift/Right Grip strength (max power) - Back and leg muscles strength .(Hassanain, 2004)

- Special judo fitness (SJFT): This test was designed by Strekowitz (1995) and was used by several researchers. It is used it in the Egyptian environment (Baioumy \& Ghazy, 2015). The test lasts for three boots (15 sec $-30 \mathrm{sec}-30$ sec) with $10 \mathrm{sec}$ rest interval between each two boots. A judoka is required to throw two opponents for as many times as possible during the duration of the boot using (Ippon-Seoi-Nage). Heart rate was measured immediately after the test and 1 minute after the test. The special judo fitness index is calculated as: (heart rate immediately after test + heart rate 1 minute after test)/ number of throws. As the index decreases this means the performance level is better.

\section{The training Program:}

Training loads were planned with special consideration to the re-taper stage until competition. Total duration of the program was (8) weeks with the last two weeks dedicated for re-taper (weeks 7 and 8).(32 units - 4 units per week). Training cycles were as follows:

a) Training cycle for weeks $1 \& 2$ : this was a preliminary cycle to improve the physiological efficiency related to various types of endurance, speed strength, flexibility and technical performance with special concentration on correct skill performance, especially for specific skills. Training volume was high while intensity was moderate.

b) Training cycle for weeks $3 \& 4$ : This basic cycle was to improve general and specific preparation of physiological abilities and basic physical qualities in addition to improving technical, tactical and psychological performance. Training load was high and intensity was $\max$. 
c) Training cycle for week 5: This transitive (testing) cycle was used to inter the competition cycle as competitive exercises increased with moderate training volume and sub-max to max intensity.

d) Training cycle for week 6: This pre-competition cycle concentrated on correcting errors in performance and improving technical, tactical and psychological performance. Training load was low with sub-max intensity.

e) Training cycle for week $7 \& 8$ : Competitive training and re-taper load were used to maintain athletic shape and recovering from fatigue resulting from previous exercises.

\section{Researchers concentrated on the qualities of load and form of training program as follows:}

- The researchers instructed judokas about competition and training loads and intensity during this stage in addition to warm-up and recovery during competition.

- Specific technical exercises were identified for each judoka either in standing or floor positions.

- Competitive challenges faced by judokas were identified so that suitable planning and training form them can be applied before competition.

- Each judoka was trained on linking skills as specialized motor patterns. Judokas were training on mastering the suite grip (Kumi-Kata) according to rule modifications.

- Competitive exercises (attack - defense) and standing and floor fight exercises were applied and all scores were recorded.

- Exercise duration ranged from $15 \mathrm{sec}$ to 2 minutes. Judokas were encouraged to seriously inter the last stage before competition.

- Re-taper load was gradually decreased in linear manner to allow the body to recover from fatigue resulting from physical, functional and technical performances during training. This allows judokas to improve their performance level while maintaining their physical and technical abilities acquired during training.

- Re-taper stage focuses on specific skills and technical performance of each judoka according to her abilities in addition to special judo fitness factors like strength endurance, speed strength and muscular strength. This can be done through basic endurance training and threshold endurance training in addition to strength endurance and speed strength exercises.

- Performance velocity was maintained near it levels before re-taper with allowing any increases to max velocity to compensate the decrease in training volume except for small sets of speed exercises related to specific skills. Increasing velocity during taper delays recovery and is a common mistake among coaches.

- Competitive and match exercises were decreased gradually so that judokas do not lose competitive endurance and cardio-respiratory endurance acquired. This can be done through endurance and speed exercises while maintaining these exercises close to its levels for the near period before taper.

- No comments were given concerning performance technique of skills all along the taper stage as this may have negative effects. Judokas were assured that they should decrease their caloric intake during taper so that fatty tissues do not accumulate due to decreased training.

- Researchers focused on strength exercises and regulations concerning nutrition, hydration and weight management during re-taper (Al-Qot 2013). Regular consult with judokas through feedback was maintained to increase their motivation (Kherbit \& Abd El-Fattah 2016).

- Duration of the four training units was gradually decreased from 120 to 60 minutes during taper as seen in table (1).

Table (1)

The Re-taper Program (low volume - high intensity)

\begin{tabular}{|c|c|c|c|c|c|c|c|c|c|}
\hline \multirow{2}{*}{\multicolumn{2}{|c|}{\begin{tabular}{|c|} 
Load shape \\
Week before competition
\end{tabular}}} & \multicolumn{8}{|c|}{ Re-TAPER } \\
\hline & & \multicolumn{4}{|c|}{2} & \multicolumn{4}{|c|}{1} \\
\hline \multicolumn{2}{|c|}{ Unit duration } & $120 \mathrm{~min}$ & $100 \mathrm{~min}$ & $100 \mathrm{~min}$ & $90 \mathrm{~min}$ & $80 \mathrm{~min}$ & $80 \mathrm{~min}$ & $70 \mathrm{~min}$ & $60 \mathrm{~min}$ \\
\hline \multicolumn{2}{|c|}{ Load level } & \multicolumn{4}{|c|}{ Moderate } & \multicolumn{4}{|c|}{ Moderate } \\
\hline \multicolumn{2}{|c|}{ Load intensity } & \multicolumn{4}{|c|}{$70-80 \%$} & \multicolumn{4}{|c|}{$60-70 \%$} \\
\hline \multirow{2}{*}{ 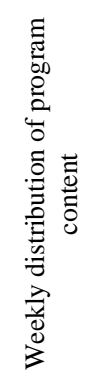 } & $\begin{array}{l}\text { Technical } \\
\text { exercises }\end{array}$ & \multicolumn{4}{|c|}{$\begin{array}{l}\text { Specific skills with repetitive exercises with max } \\
\text { speed (Uchi-Komi) with gradual duration from } 15 \\
\text { sec to } 10 \mathrm{sec}+\text { varied training (technical / tactical), } \\
\text { attack/defense skills (attack strategies with complex } \\
\text { patterns and feint - linking standing and floor } \\
\text { fight), specific skill of throwing from movement. } \\
\text { (judoka feels moderate fatigue) }\end{array}$} & \multicolumn{4}{|c|}{$\begin{array}{l}\text { Specific skills with repetitive exercises with max } \\
\text { speed (Uchi-Komi) with gradual duration from } 15 \\
\text { sec to } 10 \mathrm{sec}+\text { varied training (technical / tactical), } \\
\text { attack/defense skills (attack strategies with complex } \\
\text { patterns and feint - linking standing and floor } \\
\text { fight), specific skill of throwing from movement. } \\
\text { (judoka feels moderate fatigue) }\end{array}$} \\
\hline & $\begin{array}{l}\text { Competitive } \\
\text { exercises }\end{array}$ & \multicolumn{4}{|c|}{$\begin{array}{l}\text { 2-1 min gradually of competitive exercises from } \\
\text { standing and on floor } \\
\text { 3-2 min of match exercises with rest of } 2 \mathrm{~min} \times 6 \text { sets } \\
\text { to } 4 \text { sets gradually }\end{array}$} & \multicolumn{4}{|c|}{$\begin{array}{l}\text { 2-1 min gradually of competitive exercises from } \\
\text { standing and on floor } \\
\text { 3-2 min of match exercises with rest of } 2 \text { min x } 6 \text { sets } \\
\text { to } 4 \text { sets gradually }\end{array}$} \\
\hline
\end{tabular}


Pre-measurements for growth factors, physical tests and participants as seen in table (2).

SJFT (with throwing and pulse) were taken for

Table (2)

Statistical Significance of Participants Descriptive Data $(n=6)$

\begin{tabular}{|c|c|c|c|c|c|c|c|c|}
\hline \multicolumn{3}{|c|}{ Variables } & Measurement & Mean & Median & SD & Kurtosis & Squewness \\
\hline$\tilde{b}$ & \multicolumn{2}{|c|}{ Age } & Year/month & 20.03 & 20.10 & 1.02 & -0.15 & -0.28 \\
\hline ల్లు & \multicolumn{2}{|c|}{ Height } & $\mathrm{Cm}$ & 161.00 & 162.00 & 2.90 & -1.79 & -0.59 \\
\hline 胥 & \multicolumn{2}{|c|}{ Weight } & $\mathrm{Kg}$ & 55.67 & 56.50 & 4.37 & -1.55 & -0.33 \\
\hline 苞 & \multicolumn{2}{|c|}{ Training period } & Year/month & 9.33 & 9.50 & 0.82 & -0.30 & -0.86 \\
\hline \multirow{6}{*}{ 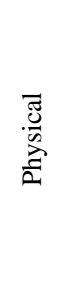 } & \multicolumn{2}{|c|}{ Vertical jump } & $\mathrm{Cm}$ & 30.83 & 30.50 & 1.47 & -0.86 & 0.42 \\
\hline & \multicolumn{2}{|c|}{ Standing Long Jump } & M & 191.00 & 194.00 & 9.25 & -1.84 & -0.67 \\
\hline & \multirow{2}{*}{ Grip strength } & right & $\mathrm{Kg}$ & 26.83 & 26.50 & 1.94 & -0.06 & 0.84 \\
\hline & & lift & $\mathrm{Kg}$ & 23.67 & 24.00 & 1.03 & 0.59 & -0.67 \\
\hline & \multicolumn{2}{|c|}{ Thigh muscles strength } & $\mathrm{Kg}$ & 77.83 & 80.00 & 10.48 & 0.00 & -0.38 \\
\hline & \multicolumn{2}{|c|}{ Back muscles strength } & $\mathrm{Kg}$ & 51.67 & 50.50 & 6.59 & 2.14 & 1.58 \\
\hline \multirow{4}{*}{ 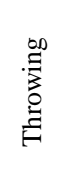 } & \multicolumn{2}{|c|}{ Throws in $15 \mathrm{sec}$} & Number & 4.67 & 5.00 & 0.52 & -1.88 & -0.97 \\
\hline & \multicolumn{2}{|c|}{ Throws in $30 \mathrm{sec}$} & Number & 9.33 & 9.00 & 0.49 & 1.27 & 1.04 \\
\hline & \multicolumn{2}{|c|}{ Throws in $30 \mathrm{sec}$} & Number & 8.67 & 9.00 & 0.52 & -1.79 & -0.92 \\
\hline & \multicolumn{2}{|c|}{ Sum of throws } & Number & 22.67 & 23.00 & 1.03 & 0.59 & -0.67 \\
\hline \multirow{2}{*}{ 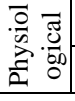 } & \multicolumn{2}{|c|}{ Pulse rate Immediately after throwing } & PBM & 181.00 & 179.50 & 5.22 & 0.88 & 1.18 \\
\hline & \multicolumn{2}{|c|}{ Pulse rate $1 \mathrm{~min}$ after effort } & PBM & 154.67 & 154.00 & 11.18 & 2.37 & 1.35 \\
\hline \multicolumn{3}{|c|}{ SJFT } & Point & 14.86 & 14.63 & 1.34 & 2.71 & 1.55 \\
\hline
\end{tabular}

Table (2) indicated that kurtosis values for participants were between $3 \pm$ indicated that data was free of radical distributions.

Post-measurements were taken for participants after the main application of the program following the same protocol of pre-measurements.

\section{Statistical treatment:}

Mean - SD - Median - kurtosis - Squewness Correlation coefficient - T.test - Variance percentage - $\rceil 2$ - Effect size according to Cohen's equation.

\section{Results:}

Table (3)

Difference significance, improvement percentages and effect size according to Cohen's equation for participants on physical tests $(n=6)$

\begin{tabular}{|c|c|c|c|c|c|c|c|c|c|c|c|c|}
\hline \multirow{2}{*}{\multicolumn{2}{|c|}{ Physical variables }} & \multirow{2}{*}{ Measurement } & \multicolumn{2}{|c|}{ Pre- } & \multicolumn{2}{|c|}{ Post- } & \multirow{2}{*}{$\begin{array}{c}\text { Means } \\
\text { Difference }\end{array}$} & \multirow{2}{*}{$\begin{array}{c}\text { Standard } \\
\text { Error }\end{array}$} & \multirow{2}{*}{$\mathrm{T}$} & \multirow{2}{*}{ Variance $(\%)$} & \multirow{2}{*}{$\eta 2$} & \multirow{2}{*}{ Effect Size } \\
\hline & & & Mean & $\mathrm{SD} \pm$ & Mean & $\mathrm{SD} \pm$ & & & & & & \\
\hline \multicolumn{2}{|c|}{ Vertical jump } & $\mathrm{Cm}$ & 30.83 & 1.47 & 35.17 & 1.72 & 4.33 & 0.49 & $8.76^{*}$ & 14.05 & 0.94 & 3.85 \\
\hline \multicolumn{2}{|c|}{ Standing Long Jump } & M & 191.00 & 9.25 & 201.33 & 4.76 & 10.33 & 2.44 & $4.23 *$ & 5.41 & 0.78 & 2.57 \\
\hline \multirow{2}{*}{ Grip strength } & right & $\mathrm{Kg}$ & 26.83 & 1.94 & 31.33 & 2.16 & 4.50 & 0.43 & $10.51 *$ & 16.77 & 0.96 & 4.12 \\
\hline & lift & $\mathrm{Kg}$ & 23.67 & 1.03 & 28.50 & 1.05 & 4.83 & 0.54 & $8.91 *$ & 20.42 & 0.94 & 3.66 \\
\hline \multicolumn{2}{|c|}{ Thigh muscles strength } & $\mathrm{Kg}$ & 77.83 & 10.48 & 85.17 & 8.52 & 7.33 & 1.12 & $6.57 *$ & 9.42 & 0.90 & 2.87 \\
\hline \multicolumn{2}{|c|}{ Back muscles strength } & $\mathrm{Kg}$ & 51.67 & 6.59 & 58.17 & 5.53 & 6.50 & 0.99 & $* 6.55$ & 12.58 & 0.90 & 2.58 \\
\hline
\end{tabular}

$\mathrm{T}$ table value on $\mathrm{P} \leq 0.05=2.01$

Effect size: -0.20 low -0.50 moderate -0.80 high

Table (3) indicated statistically significant differences between the pre- and post-measurements with high effect size for participants on physical tests in favor of postmeasurements. 
Table (4)

Difference significance, improvement percentages and effect size according to Cohen's equation for participants on SJFT and technical tests $(n=6)$

\begin{tabular}{|c|c|c|c|c|c|c|c|c|c|c|c|c|}
\hline \multirow{2}{*}{\multicolumn{2}{|c|}{ Technical variables }} & \multirow{3}{*}{\begin{tabular}{|c} 
Measurement \\
Number
\end{tabular}} & \multicolumn{2}{|c|}{ Pre- } & \multicolumn{2}{|c|}{ Post- } & \multirow{3}{*}{$\begin{array}{c}\begin{array}{c}\text { Means } \\
\text { Difference }\end{array} \\
1.17\end{array}$} & \multirow{3}{*}{$\begin{array}{c}\begin{array}{c}\text { Standard } \\
\text { Error }\end{array} \\
0.17\end{array}$} & \multirow{3}{*}{\begin{tabular}{|c|}
$\mathrm{T}$ \\
$7.00 *$ \\
\end{tabular}} & \multirow{3}{*}{$\begin{array}{c}\begin{array}{c}\text { Variance } \\
(\%)\end{array} \\
25.00\end{array}$} & \multirow{3}{*}{$\begin{array}{l}12 \\
0.91\end{array}$} & \multirow{3}{*}{$\begin{array}{c}\begin{array}{c}\text { Effect } \\
\text { Size }\end{array} \\
3.19\end{array}$} \\
\hline & & & \multirow{2}{*}{\begin{tabular}{|c|} 
Mean \\
4.67 \\
\end{tabular}} & \multirow{2}{*}{\begin{tabular}{|l|}
$\mathrm{SD} \pm$ \\
0.52 \\
\end{tabular}} & \multirow{2}{*}{\begin{tabular}{|c|} 
Mean \\
5.83
\end{tabular}} & \multirow{2}{*}{\begin{tabular}{|l|}
$\mathrm{SD} \pm$ \\
0.75 \\
\end{tabular}} & & & & & & \\
\hline \multirow{4}{*}{ Throwing } & $15 \mathrm{sec}$ & & & & & & & & & & & \\
\hline & $30 \mathrm{sec}$ & Number & 9.33 & 0.49 & 10.50 & 0.84 & 1.17 & 0.17 & $7.00 *$ & 12.50 & 0.91 & 2.85 \\
\hline & $30 \mathrm{sec}$ & Number & 8.67 & 0.52 & 11.17 & 0.67 & 2.50 & 0.32 & $7.81 *$ & 28.85 & 0.92 & 3.62 \\
\hline & Sum & Number & 22.67 & 1.03 & 27.50 & 0.75 & 4.83 & 0.49 & $9.86 *$ & 21.32 & 0.95 & 3.37 \\
\hline \multirow{2}{*}{ Pulse rate } & $\begin{array}{l}\text { Immediately after } \\
\text { throwing }\end{array}$ & PBM & 181.00 & 5.22 & 178.33 & 3.78 & 2.67 & 0.84 & $3.16^{*}$ & 1.47 & 0.67 & 1.12 \\
\hline & $1 \mathrm{~min}$ after effort & PBM & 154.67 & 11.18 & $150.50 \mid$ & 12.50 & 4.17 & 0.79 & $5.26 *$ & 2.69 & 0.85 & 1.96 \\
\hline \multicolumn{2}{|r|}{ SJFT } & Point & 14.86 & 1.34 & 12.84 & 1.09 & 2.01 & 0.33 & $6.10 *$ & 13.54 & 0.88 & 1.83 \\
\hline
\end{tabular}

$\mathrm{T}$ table value on $\mathrm{P} \leq 0.05=2.01$

Effect size: -0.20 low -0.50 moderate -0.80 high

Table (4) indicated statistically significant differences between the pre- and post-measurements with high effect size for participants on SJFT and technical tests in favor of post-measurements.

\section{Discussion:}

Table (3) indicated significant improvements in physical abilities of participants through comparison on pre- and post-measurements. Improvement percentage and high effects size were noted for all physical variables as the least value was $(5.41 \%)$ with high effect size $(2.57)$ for Standing Long Jump while the highest value was (20.42\%) with high effect size (4.12) for grip strength (right). Torfa (2001) and Baioumy \& Ghazy (2015) agreed that all components of strength are important for judokas. Speed strength and max strength affect the technical performance of throws with full power, speed and control of judokas over throws. Al-Qot (2013) indicated that improving performance during taper is clear in power output. Improvement percentage in strength varies according to specific requirements of each sports activity. Karimi et al (2014) indicated that physical performance improves after taper.

The researchers think that this improvement is due to the re-taper program. This is consistent with results of Pritchard,et al.(2015) who indicated that taper is an effective strategy for improving max strength as decreasing training volume by (30-70\%) with decreased frequency or duration and maintaining or slightly increasing intensity is most suitable and most effective for improving max strength.

Progressive training loads of re-taper affects speed strength, grip strength and legs and back strength positively. These is especially true for grip and leg which a judoka uses most frequently and are more vulnerable to fatigue due to over use during training and competition. This indicates the positive effects of re-taper on compensation to reach peak performance during competitions. Judo includes a huge number of moves requiring strong muscular eccentric contractions that lead to muscle inflammation manifested as muscle pain during heavy training. Using taper loads decreases muscular fatigue and relieves pain (Papacosta, et al. 2013).

Abd El-Zaher \& Baoumy (2015) indicated that increased training loads during summit training require a decrease in training loads during taper for competition as a preventive measure for maintaining the condition of the immune system and health status of the athlete. Baioumy \& Ghazy (2015) indicated that taper has positive effects on physical variables of a judoka. It affects technical preparation stages in judo. The attacking judoka needs control over the opponent as she starts with static strength and then dynamic strength during execution. This indicates the importance of strength for judokas according to the stages of technical performance for each skill. This proves the first hypothesis.

Table (4) indicated significant improvements in SJFT of participants through comparison on pre- and postmeasurements. Improvement percentage and high effects size were noted for all SJFT for both throwing and pulse rate. Throwing results indicated improvement percentages of $(25 \%)$ with high effect size (3.19) in throwing in $15 \mathrm{sec}$, $(12.50 \%)$ with high effects size (2.85) in throwing in 30 sec and (28.85\%) with high effect size (3.62) in the last throwing in $30 \mathrm{sec}$. total improvement in throwing was $(21.32 \%)$ with high effect size (3.37). this proves the positive effects of the re-taper program on throwing (15 $\mathrm{sec}-30 \mathrm{sec}-30 \mathrm{sec})$ with rest intervals of $(10 \mathrm{sec})$. this 
also proves the variance of motor performance of judokas according to individual differences. Nevertheless, their physical abilities related to technical performance varied according to the speed and continuity of aerobic and anaerobic work. During throwing muscles exert dynamic work characterized by speed strength which in most cases is followed by static work. Researchers indicated that although high levels of physical abilities are required for repetitive technical performance, judokas should enjoy mental abilities like enthusiasm, patience, persistence and fighting spirit due to their significant effects over performance. Papcosta et.al (2013) indicated that after high training loads, the performance level of judokas improves with two weeks of taper especially for SJFT due to improved anaerobic abilities and compensation of muscular power. Al-Qot (2013) indicated that taper is based on reaching the competition day with fully functional abilities. Most coaches recommend decreasing training volume and maintaining training intensity so that decrease is $20-60 \%$ of training volume.

Table (4) also indicated that improvement percentage for pulse immediately after throwing was $(1.47 \%)$ with high effect size (1.12) while the same percentage was $(2.69 \%)$ for $1 \mathrm{~min}$ after throwing with high effect size (1.96). these results indicated that total improvements in SJFT was $(13.4 \%)$ with high effect size (1.83). Pulse rates increase during throwing and breathing is not regular as judokas held their breath during static muscular contraction and therefore its frequency increases after release. Elite judokas can regulate their breath more than beginners. Pulse is an indicator for the training status of judokas as it can be measured in various times like recovering from effort or during effort to identify its nature. Al-Qot (2013) indicated that studies related to the effects of taper on max heart rate showed perplexing results as some showed its decrease while others indicated it maintained the same level or even increased after taper. In addition, there is a slight variance in sub-maximal heart rate after taper and this is due to variations among sports activities.

A coach should organize and plan training load to help athletes achieve their optimum performance level during main competition. This is one of the challenges and problems facing coaches as athletes reach peak performance very early before main competition due to constant pushing for highest possible levels and without any arrangements or time for reloading (Kherbit \& Abd El-Fattah. 2016).

Good planning for athletes' preparation requires organizing training load variables during the training season according to each stage of training until competition stage.The main aim of coaches and athletes is to increase competitive abilities to its max and to design a good training program that guarantees optimum peak performance during major competitions (Mirzaei, et.al., 2009).

Fukuda et.al.(2013) indicated that taper improves physical and technical performance of judokas. Karimi et.al.(2013) indicated taper improves physical performance and mental status of athletes. (Baioumy \& Ghazy,2015) indicated that judokas should pass through two weeks of taper before major competitions to reach peak performance. In general, training loads should decrease to enable judokas recover from metabolic byproducts and fatigue before competition.

It is clear that SJFT index improved after taper for elite female collegiate judokas as decreased training volume to moderate and maintained training intensity compensated judokas with enough time for mixing passive and active rest which in turn enabled them to maintain athletic shape. SJFT index indicated that re-taper program helped preparing elite female Collegiate judokas for competitions more effectively. This proves the second hypothesis.

\section{Conclusions:}

1- Re-taper program showed statistically significant differences between pre- and post-measurements of physical variables with improvement percentages ranging from $(5.41 \%)$ to $(20.42 \%)$ and high effect size ranging from (2.57) to (4.12) in favor of post-measurements.

2- Re-taper program showed statistically significant differences between pre- and post-measurements of number of throws with improvement percentages ranging from $(12.5 \%)$ to $(28.85 \%)$ and high effect size ranging from (2.85) to (3.62) in favor of post-measurements.

3- Re-taper program showed statistically significant differences between pre- and post-measurements of pulse rates with improvement percentages ranging from $(1.47 \%)$ to $(2.69 \%)$ and high effect size ranging from (1.12) to (1.96) in favor of post-measurements.

4- Re-taper program showed statistically significant differences between pre- and post-measurements of SJFT with improvement percentage of $(1.54 \%)$ and high effect size (1.83) in favor of post-measurements.

5- Results indicated that SJFT index for participants was (12.84) which means that special judo fitness of participants is very high after re-taper. 


\section{Recommendations:}

1- Good planning of suitable taper programs for judokas before any competition is required to benefit from the physical and technical advantages of taper.

2- Collegiate coaches should carefully monitor the training programs of their teams during the training season to decide the best taper mood suitable for their teams.

\section{References:}

1- Abd El-Zaher, Mohamed Mahmoud \& Baoumy, Mamdouh Mohamed (2015): Effects of variance of summit taper duration on some hormonal responses and Muscular Inflammation Indicators. The International Scientific Journal Of Physical Education And Sport Sciences (ISJESS)- Egypt (in Arabic), Vol.75, 502-522

2- Al-Qot, Mohamed, A. (2013). Summit Taper for Athletes. Book Center Press - Cairo - Egypt (in Arabic), $5,14-15,58,94,112$

3- Anzano, A. P., \& Llorens, J. L. C. (1997). Estudio de la estructura temporal del combate de judo. Apunts: educación física y deportes, (47), 32-39. (in Spanish, English abstract)

4- Baioumy, M. E., \& Ghazy, A. M. (2015) Effects of a Major Taper Training Program on some Physical Variables and Specific Fitness for Judokas. The International Scientific Journal Of Physical Education And Sport Sciences (ISJESS), Volume (2) Issue (2) Sep,31-40

5- Bosquet, L., Montpetit, J., Arvisais, D., \& Mujika, I. (2007). Effects of tapering on performance: a metaanalysis. Medicine and science in sports and exercise,39(8), 1358-1365.

6- Coutts, A, Reaburn, P, Piva, TJ, and Murphy, A. (2007). Changes in selected biochemical, muscular strength, power, and endurance measures during deliberate overreaching and tapering in rugby league players. Int $\mathbf{J}$ Sports Med, 28, 116-124

7- Farhangimaleki, N., Zehsaz, F., \& Tiidus, P. M. (2009). The effect of tapering period on plasma pro-inflammatory cytokine levels and performance in elite male cyclists. Journal of sports science \& medicine, 8(4), 600606.

8- Franchini, E., Del Vecchio, F. B., Matsushigue, K. A., \& Artioli, G. G. (2011). Physiological profiles of elite judo athletes. Sports Medicine, 41(2), 147-166.

9- Fukuda, D. H., Stout, J. R., Kendall, K. L., Smith, A. E., Wray, M. E., \& Hetrick, R. P. (2013). The effects of tournament preparation on anthropometric and sportspecific performance measures in youth judo athletes. The Journal of Strength \& Conditioning Research, 27(2), 331339.

10- Hasanain, Mohamed,S. (2004).Measurement and Evaluation in Physical Education and Sport. 6th ED - Part One. Dar Al-Fikr Al-Araby - Cairo - Egypt (in Arabic) ,209-211, 304, 307

11- Hellard, P., Avalos, M., Hausswirth, C., Pyne, D., Toussaint, J. F., \& Mujika, I. (2013). Identifying optimal overload and taper in elite swimmers over time. Journal of sports science \& medicine, 12(4), 668-678

12- Houmard, J. A., Scott, B. K., Justice, C. L., \& Chenier, T. C. (1994). The effects of taper on performance in distance runners. Medicine and science in sports and exercise, 26(5), 624-631.

13- Karimi, M., Bakht, N., \& Mk, V. M. (2014). The Effect Of Two Types Of Tapering On Plasma Anabolic And Catabolic Steroid Hormones Following Incremental Training In Elite Male Wrestlers. Introducing the International Journal of Wrestling Science, 1, 7-10

14- Karimi, M., Keshavarz, S., Ansari, M. J., \& Etaati, A. (2013). Mood Changes During A Period of Incremental Training and Following Tapering Strategies in Elite Male Wrestlers. International Journal of Wrestling Science, 3(1), 48-57.

15- Kherbit, Risan \& Abd El-Fattah, Abu Al-Ela (2016): Sports Training. Book Center Press, Cairo - Egypt (in Arabic) , 553-554

16- Mehranpour, A. B., Supaporn, S., Hasani, S. H., \& Witid, M. (2015). Effect of two tapering methods on interleukin-6, cortisol and performance in elite male wrestler, Pedagogics, psychology, medical-biological problems of physical training and sports , (8),82-88

17- Mirzaei, B., Curby, D. G., Rahmani-Nia, F., \& Moghadasi, M. (2009). Physiological profile of elite Iranian junior freestyle wrestlers. The Journal of Strength \& Conditioning Research, 23(8), 2339-2344.

18- Mujika, I., \& Padilla, S. (2003). Scientific bases for precompetition tapering strategies. Medicine and science in sports and exercise, 35(7), 1182-1187.

19- Mujika, I., Padilla, S., Pyne, D., \& Busso, T. (2004). Physiological changes associated with the pre-event taper in athletes. Sports Medicine, 34(13), 891-927.

20- Neary, J. P., Bhambhani, Y. N., \& McKenzie, D. C. (2003). Effects of different stepwise reduction taper 
protocols on cycling performance. Canadian journal of applied physiology, 28(4), 576-587.

21- Nishioka, H. (2000). Judo: heart and soul, Ohara Publications, Incorporated, U.SA, 201

22- Papacosta, E., Gleeson, M., \& Nassis, G. P. (2013). Salivary Hormones, IgA, and Performance During Intense Training and Tapering in Judo Athletes. The Journal of Strength \& Conditioning Research, 27(9), 2569-2580.

23- Pritchard, H., Keogh, J., Barnes, M., \& McGuigan, M. (2015). Effects and mechanisms of tapering in maximizing muscular strength. Strength \& Conditioning Journal, 37(2), 72-83.
24- Sterkowicz, S. (1995). Test specjalnej sprawności ruchowej w judo [Special Judo Fitness Test. Antropomotoryka] 12: 29-44 (in Polish, English abstract)

25- Torfa, Morad I. (2001). Judo between theory and practice. Dar Al-Fikr Al-Araby - Cairo - Egypt (in Arabic) , 437

26- Umeda, T., Suzukawa, K., Takahashi, I., Yamamoto, Y., Tanabe, M., Kojima, A. \& Sugawara, N. (2008). Effects of intense exercise on the physiological and mental condition of female university judoists during a training camp. Journal of sports sciences, 26(9), 897-904. 